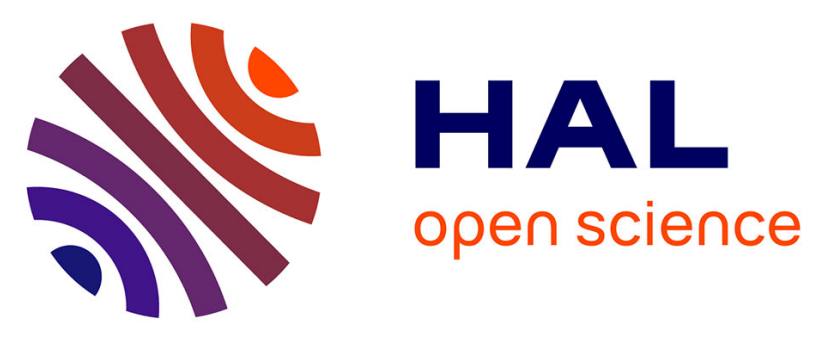

\title{
Multi-physics modeling and optimization of a multi-V-shape IPM with concentrated winding
}

Paul Akiki, Maya Hage Hassan, Philippe Dessante, Jean-Claude Vannier, Mohamed Bensetti, Dany Prieto, Mike Mcclelland

\section{- To cite this version:}

Paul Akiki, Maya Hage Hassan, Philippe Dessante, Jean-Claude Vannier, Mohamed Bensetti, et al.. Multi-physics modeling and optimization of a multi-V-shape IPM with concentrated winding. 2017 IEEE International Electric Machines and Drives Conference (IEMDC), May 2017, Miami, FL, United States. pp.1-7, 10.1109/IEMDC.2017.8002060 . hal-01677520

\section{HAL Id: hal-01677520}

https://hal-centralesupelec.archives-ouvertes.fr/hal-01677520

Submitted on 11 Mar 2020

HAL is a multi-disciplinary open access archive for the deposit and dissemination of scientific research documents, whether they are published or not. The documents may come from teaching and research institutions in France or abroad, or from public or private research centers.
L'archive ouverte pluridisciplinaire HAL, est destinée au dépôt et à la diffusion de documents scientifiques de niveau recherche, publiés ou non, émanant des établissements d'enseignement et de recherche français ou étrangers, des laboratoires publics ou privés. 


\title{
Multi-Physics Modeling and Optimization of a Multi-V-Shape IPM with Concentrated Winding
}

\author{
Paul Akiki ${ }^{1,2}$, Maya Hage-Hassan ${ }^{1}$, Philippe Dessante ${ }^{1}$, Jean-Claude Vannier ${ }^{1}$, \\ Mohamed Bensetti ${ }^{1}$, Dany Prieto ${ }^{2}$, Mike McClelland ${ }^{2}$ \\ ${ }^{1}$ GeePs | Group of electrical engineering-Paris, UMR CNRS 8507, CentraleSupélec, Univ.Paris-Sud, Université Paris-Saclay, \\ Sorbonne Universités, UPMC Univ Paris 06, 3 \& 11 rue Joliot-Curie, 91192 Gif-sur-Yvette, France \\ ${ }^{2}$ Leroy Somer Motors, Boulevard Marcellin Leroy,16000 Angoulême, France
}

\begin{abstract}
In this paper a coupled multi-physics model is proposed for a multi-V-shape Interior Permanent Magnet (IPM) motor with concentrated winding. A non-linear magnetic model computes the flux density in the stator and the rotor and delivers the torque, the internal power factor and the internal voltage. It is coupled with an electrical model that computes the power factor and the voltage at the motor terminals by considering the resistance and the leakage inductance. A loss model is developed in order to calculate the copper and the iron losses. They are used as inputs to a thermal model that computes the temperature of the motor. Finally, a multi-objective optimization is carried out in order to design the motor for a high torque and low speed application.
\end{abstract}

Keywords-Concentrated winding, Electrical machines, IPM motor, Multi-physics model, Multi-V-shape magnets, Optimization

\section{INTRODUCTION}

Direct drive motors gained great attention recently not only in the field of electrical vehicles but also in high torque and low speed applications. Traditionally, high speed motors were connected to the drive system through a gear box that reduces the speed and increases the delivered torque. The low reliability and the reduced efficiency of the conventional solution led the researchers to investigate direct drive motors with high torque density. Permanent magnet motors with rare earth magnets provided a very good alternative and have been widely studied and used during the last decades [1]. But, these magnets suffer from high prices which led manufacturers to study new topologies that avoid or reduce the use of rare-earth materials. Authors in [2] studied the possibility of reducing the $\mathrm{NdFeB}$ magnet size while maintaining the efficiency map of the motor. Magnet-free machines such as switched reluctance and flux switching motors were compared in [3]. Non-rareearth permanent magnets such as ferrite were used as an additional torque source in synchronous reluctance motors [4], [5]. The previously mentioned structures are generally designed with distributed winding but more novel topologies with multi-V shape interior permanent magnets and concentrated tooth winding were also capable of developing a high torque at low rotational speed [6].

In this paper, the studied motor has 18 slots and 16 poles with two V-shape barriers per pole filled with ferrite magnets (Fig. 1). It is able to deliver a smooth, high torque [6]. Besides, the concentrated winding reduces the length of the end- winding which decreases the copper losses and may improve the efficiency.

This work aims to develop a multi-physics model of the motor and to optimize it in order to meet the required specifications. In the next sections, the magnetic, the electrical, the loss and the thermal models will be detailed. Finally, the coupled multi-physics model will be defined and the biobjective optimization results will be presented.

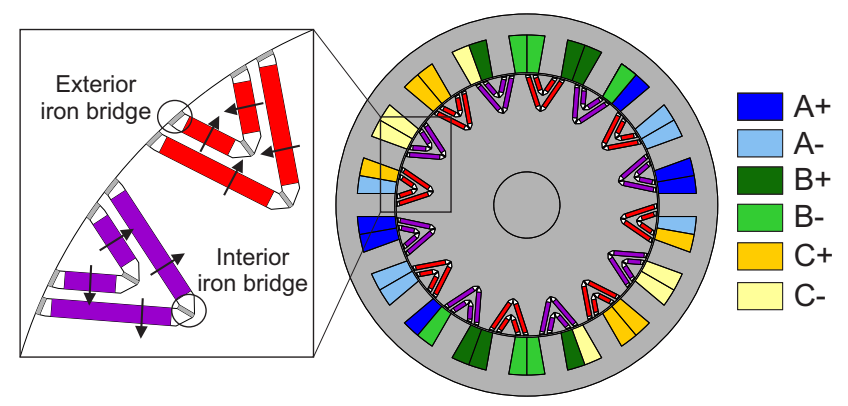

Fig. 1. Studied motor structure

\section{MAGNETIC MODEL}

The magnetic model is the one that provides the main performances of the motor in terms of torque, internal power factor and internal voltage. The model relies on two fundamental laws of electromagnetism: Ampere's theorem and the flux conservation law. Previous work gives a detailed description and analysis of the magnetic model [7]. In this article, we will present the main guidelines of the model with the results compared to a $2 \mathrm{D}$ finite element model.

\section{A. Stator flux density}

The modeled structure has a wide slot opening that allows an easier insertion of the concentrated tooth winding during the manufacturing process. The stator slotting effect is taken into account by calculating an additional air-gap length under the slot opening which leads to the total airgap length $e_{t o t}$.

Fig. 2 shows the flux lines between the airgap and the stator tooth. $\theta_{\tau s t}$ is the tooth pitch, $\theta_{s t}$ is the tooth angular span, $\theta_{i}$ is angular position of the center of the $\mathrm{i}^{\text {th }}$ tooth and $w_{\text {slot }}$ is the slot width. Additionally, the tangential leakage flux that links two adjacent teeth is taken into account. Ampere's theorem is written on paths along the tooth height $h_{s t}$ as shown in Fig. 3. 
The flux conservation law is applied between the tangential leakage flux in stator slots $\phi_{\text {lf_slot }}$ and the slot flux entering the tooth $\phi_{\text {st_slot. }}$. The stator yoke flux density is calculated using the flux conservation equation between the stator teeth and the yoke over a variation of $\Delta \theta=1^{\circ} \mathrm{elec}$ (electrical degree).

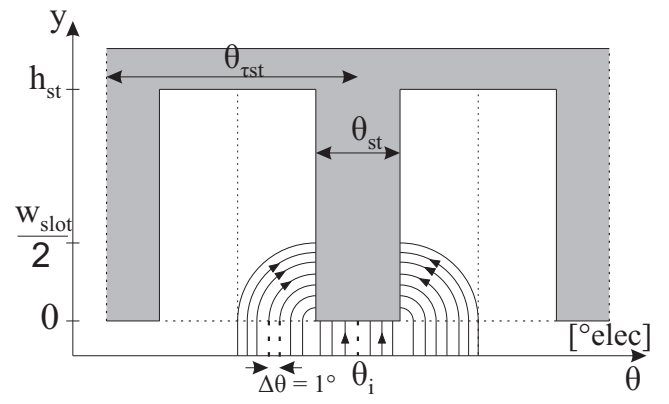

Fig. 2. Flux lines between the airgap and the stator tooth

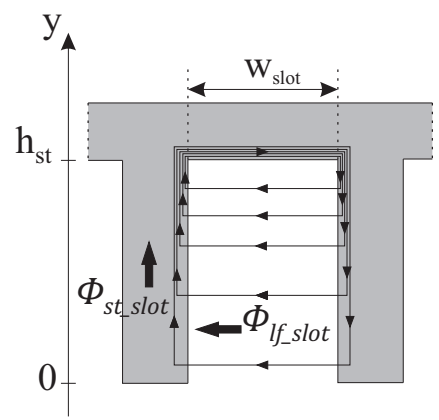

Fig. 3. Tangential leakage flux in the stator slot

\section{B. Rotor flux density}

Fig. 4 shows one rotor pole with V-shape flux-barriers that are filled with magnets. The iron piece between two fluxbarriers is called "flux-guide" (green area in Fig. 4). Each rotor pole is divided into two zones $(z=1,2)$. A linear interpolation is used between the boundary flux densities $B_{f g 0}$ and $B_{f g f}$ in order to compute the interior flux densities of each flux-guide along its mean path (Fig. 5a). The structure of the rotor presents interior and exterior iron bridges (Fig. 1). Since the iron bridges are generally saturated, the area near the exterior iron bridges is modeled separately (Fig. 5b). We assume a linear variation of the flux density between two bridges in the $\theta$-axis $\left(B_{x}(\theta)\right.$ between $B_{e b f}$ and $\left.B_{e b 0}\right)$. An average value of the flux density in the y-axis $B_{y}$ is calculated (between $B_{f g f}$ and the airgap flux density between the bridges $\left.B_{a g} a v g\right)$. Thus, the fluxguide local saturation flux density is given by:

$$
B_{\text {local }_{\text {sat }}}(\theta)=\sqrt{B_{x}(\theta)^{2}+B_{y}^{2}}
$$

\section{Equations of the global system}

The model considers the non-linearity of the ferromagnetic material. Due to magnetic symmetry, half of the machine is modeled. The analytical model computes the flux density of the airgap over one electrical period $\left(360^{\circ} \mathrm{elec}\right)$. Ampere's theorem is applied along five contours $\left(C_{1}\right.$ to $\left.C_{5}\right)$ shown in Fig. 4. For the first contour it is expressed by:

$$
\begin{aligned}
& H_{a g}^{(\theta)} e_{t o t}^{(\theta)}-H_{a g}^{(360)} e_{t o t}^{(360)}+A t_{s}^{(\theta)}-A t_{s}^{(360)} \\
& +A t_{r}^{(\theta)}-A t_{r}^{(360)}+m m f^{(\theta)}-m m f^{(360)}=0
\end{aligned}
$$

where, $m m f$ is the magnetomotive force due to the stator winding, $A t_{s}$ and $A t_{r}$ are the magnetomotive force drop in the stator (tooth + yoke) and the rotor paths respectively. The expressions of contours $\mathrm{C}_{2}$ to $\mathrm{C}_{5}$, the flux density of the interior and exterior iron bridges along with all the details of the magnetic model are given in [7].

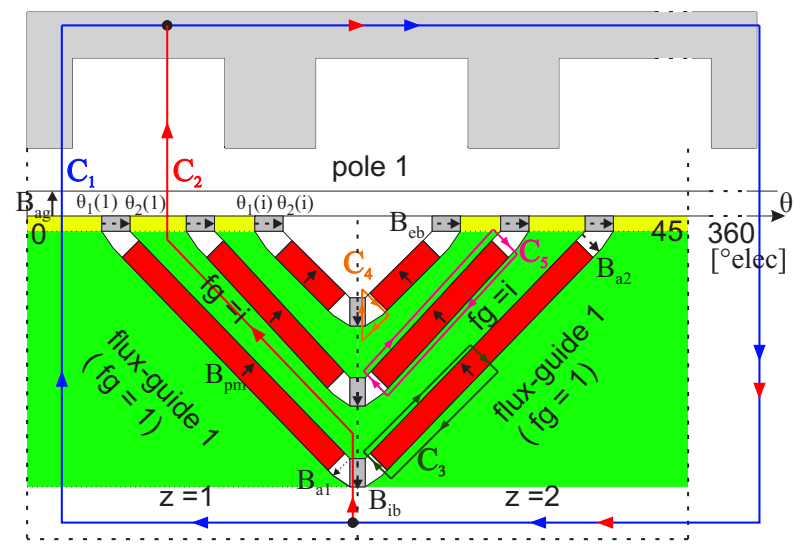

Fig. 4. Motor general schematic and flux paths

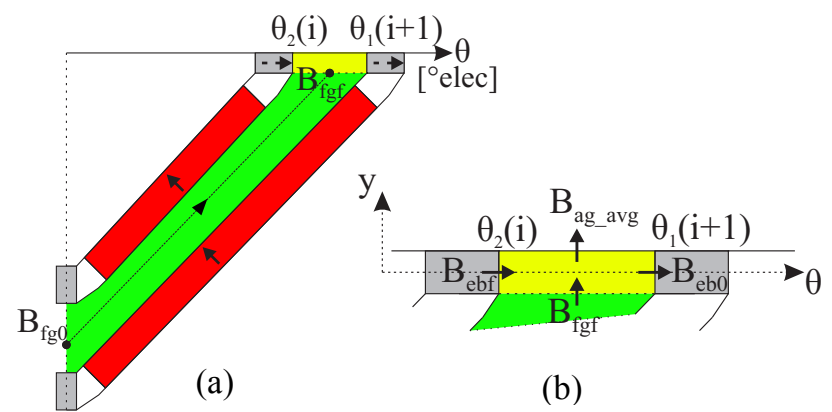

Fig. 5. Flux density mean path in a rotor flux-guide (a). Local saturation near the exterior iron bridge $(b)$

The non-linear equations of the magnetic model are solved using Broyden's method [8].

\section{Performance calculation}

The airgap flux density is used to calculate the stator phase flux linkages $\left(\phi_{a}, \phi_{b}, \phi_{c}\right)$. The slot leakage flux $\phi_{\text {st }}$ if is added to obtain the total flux linked by the stator coils. Equation (3) gives the flux linkage phase-A. For the other phases it is obtained by replacing the subscript $\mathrm{A}$ by $\mathrm{B}$ and $\mathrm{C}$.

$$
\phi_{a}=\frac{N_{c s}}{N_{c p}} N_{s} \sum_{k=1}^{m} R_{s i} L \int_{\theta_{A-k}}^{\theta_{A+{ }_{k}}} B_{a g}(\theta) d \theta+\phi_{s t_{l f}}
$$

where $\theta_{A+}$ and $\theta_{A-}$ are the center angular position of the coils A+ and A- (Fig. 1), $N_{s}$ is the number of turns per coil, $N_{c s}$ is the number of circuit in series per phase, $N_{c p}$ is the number of circuits in parallel per phase, $m$ is the number of coils per phase per electrical period, $L$ is the stack length and $R_{\mathrm{si}}$ is the stator interior radius. The $\mathrm{d}$-q axis flux linkages $\left(\phi_{d}, \phi_{q}\right)$ are then computed using Park's transformation. The average torque $\left(T_{a v g}\right)$, the internal power factor $\left(P F_{\text {int }}\right)$ and the internal voltage $\left(V_{\text {int }}\right)$ are calculated at 4 static positions for an accurate estimation [7]. They are expressed by (4), (5) and (6) respectively. 


$$
\begin{gathered}
T_{a v g}=\frac{3 p}{2}\left(\phi_{d} i_{q_{\text {int }}}-\phi_{q} i_{d_{\text {int }}}\right) \\
P F_{\text {int }}=\cos \left(\tan ^{-1}\left(-\frac{\phi_{d}}{\phi_{q}}\right)-\tan ^{-1}\left(\frac{i_{q_{\text {int }}}}{i_{d_{\text {int }}}}\right)\right) \\
V_{\text {int }}=\omega \sqrt{{\phi_{d}}^{2}+\phi_{q}{ }^{2}}
\end{gathered}
$$

\section{E. Finite element validation}

The geometry and specifications of the studied motor $M_{l}$ are reported in TABLE I. A 2D finite element model is simulated using FEMM and its results are compared with the analytical model at two current levels: $28 \mathrm{~A}$ and $43 \mathrm{~A}$ (rms). The average torque, the power factor and the voltage are given in Fig. 6a, Fig. 6b and Fig. 6c respectively.

The Analytical magnetic Model (AM) shows very good concordance with the Finite Element Analysis (FEA). The discrepancy is below $2 \%$ [7].

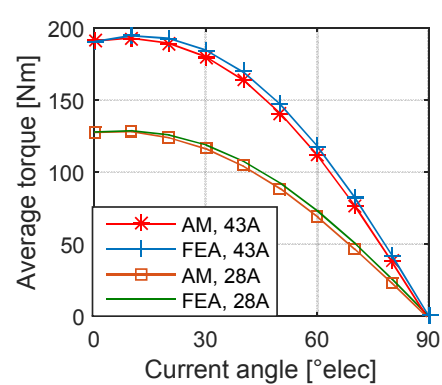

(a)

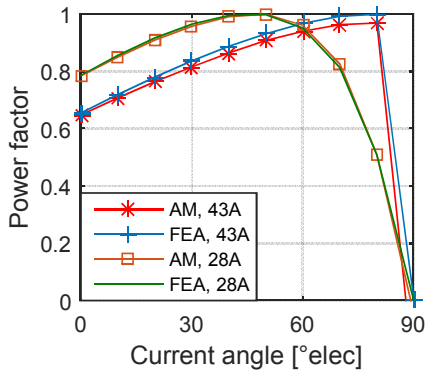

(b)

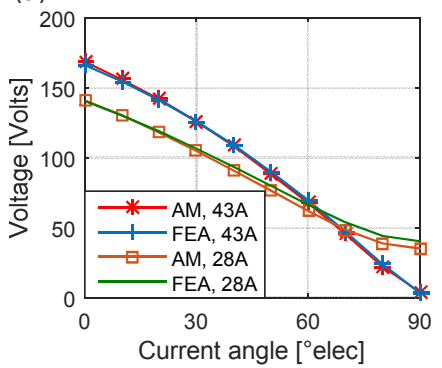

(c)

Fig. 6. Comparison of Tavg (a), PFint (b) and Vint (c) between the AM and the FEA

TABLE I. REFERENCE MOTOR GEOMETRY AND SPECIFICATIONS

\begin{tabular}{cc}
\hline \hline & $M_{1}$ \\
\hline Stator exterior radius $(\mathrm{mm})$ & 130 \\
Axial length (mm) & 200 \\
Nb. of V-shape barriers & 2 \\
Ferrite magnets remanence (T) & 0.4 \\
Rotation speed (rpm) & 500
\end{tabular}

\section{ELECTRICAL MODEL}

The magnetic model delivers the internal power factor and the internal voltage $\left(V_{\text {int }}\right)$ of the motor. However, in order to calculate the power factor and the voltage at the motor terminals we need to calculate the phase resistance $R_{p h}$ and the end-winding leakage inductance per phase $L_{e w_{p h}}$. The phases are star-connected. The electrical schematic of one phase of the motor is given in Fig. 7. The resistance per phase is given by:

$$
R_{p h}=\rho_{\text {Cu }} \frac{N_{s}^{2} l_{\text {turn }}}{K_{\text {fill }} S_{\text {coil }}} \frac{N c s}{N c p} \text { with } S_{\text {coil }}=w_{\text {coil }} \times h_{\text {coil }}
$$

where $\rho_{C u}, l_{\text {turn }}, K_{\text {fill }}, S_{\text {coil }}, w_{\text {coil }}$ and $h_{\text {coil }}$ are the copper resistivity, the average turn length, the fill factor, the coil crosssectional area, the coil width and the coil height respectively. The end-winding leakage inductance per phase is calculated using (8) given in [9] and is based on the geometry shown in Fig. 8.

$$
\begin{gathered}
L_{e w_{p h}}=\frac{\mu_{0} l_{e w} N_{s}^{2}}{2 \pi} \ln \left(\frac{r}{R_{c}}\right) \frac{N c s}{N c p} \\
\text { with } r=R_{c}+\frac{w_{c o i l}}{2}+\frac{w_{s t}}{2} \text { and } \pi R_{c}^{2}=S_{\text {coil }}
\end{gathered}
$$

where $\mu_{0}$ is the vacuum permeability and $l_{e w}$ is the endwinding average length. The iron losses $P_{i l}$ (calculated in section IV.B) are modeled by the mean of a parallel resistance $R_{i l}$ calculated as follows:

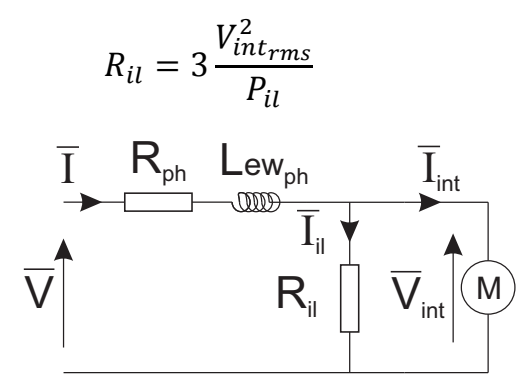

Fig. 7. Electrical schematic

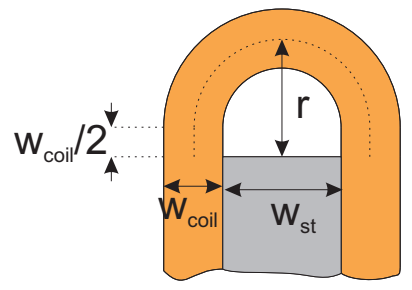

Fig. 8. End-winding geometry

The d-q axis current and voltage at the motor terminals are obtained by applying Kirchhoff's law to the circuit given in Fig. 7. This leads to the following expressions:

$$
\begin{gathered}
i_{d}=i_{d_{\text {int }}}-\left(\omega \phi_{q}\right) / R_{i l} \\
i_{q}=i_{q_{\text {int }}}+\left(\omega \phi_{d}\right) / R_{i l} \\
v_{d}=-\omega \phi_{q}+R_{p h} i_{d}-L_{e w_{p h}} \omega i_{q} \\
v_{q}=\omega \phi_{d}+R_{p h} i_{q}+L_{e w_{p h}} \omega i_{d}
\end{gathered}
$$

\section{LOSS MODEL}

The heat generation in an electrical motor is mainly caused by the losses that appear in the copper, the iron and the 
magnets. High resistivity ferrite magnets leads to negligible magnet losses [10].

\section{A. Copper losses}

$R_{p h}$ given by (7) and the current $r m s$ value per phase $I_{r m s}$ are used to calculate the copper losses as follows:

$$
P_{C u}=3 R_{p h} I_{r m s}^{2}
$$

\section{B. Iron losses}

The stator iron loss components are calculated separately for sinusoidal flux density. This can be extended to nonsinusoidal flux density by applying the principle of superposition using the following expression at the different harmonic frequencies [11]:

$$
\begin{aligned}
& P_{\text {stator }}(B, f)=k_{H} f \hat{B}^{\alpha_{i r}} \\
& +k_{E C} \sum_{k=1}^{\infty}(k f)^{\frac{3}{2}} B_{k}{ }^{2} \frac{\sinh (\gamma \sqrt{k f)}-\sin (\gamma \sqrt{k f)}}{\cosh (\gamma \sqrt{k f)}-\cos (\gamma \sqrt{k f})} \\
& +k_{E X C} f^{\frac{3}{2}} \hat{B}^{\frac{3}{2}}[W / k g]
\end{aligned}
$$

where $B_{k}$ is the amplitude of the $k^{\text {th }}$ rank of the Fourier series decomposition and $\hat{B}$ is the magnitude of the magnetic flux density. Equation (15) is applied to the stator teeth $\left(P_{s t}\right)$ and to the yoke $\left(P_{s v}\right)$ to calculate the total iron losses in the stator. The parameters $k_{H}, \alpha_{i r}, k_{E C}, \gamma$ and $k_{E X C}$ are determined by fitting the losses calculated using (15) to the manufacturer's data. The parameters obtained for the M400P50 sheet steel, used in this design, are reported in TABLE II.

The stator iron loss model was compared to a $2 \mathrm{D}$ finite element model using $\mathrm{JMAG}^{\circledR}$. The results for the motor $M_{1}$ (TABLE I) at $43 \mathrm{~A}$ are given in Fig. 9. It shows a good estimation of the stator iron losses at different current angle.

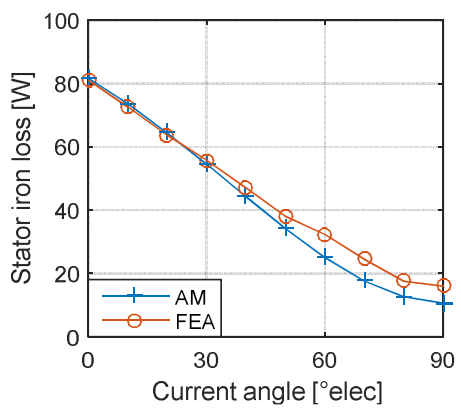

Fig. 9. Comparison of the stator iron loss between the AM and the FEA

On the rotor side, the iron losses can reach significant values due to the presence of the concentrated tooth winding. In fact, the space harmonics component of the stator winding can mainly cause eddy current losses in the rotor [10]. In order to take the rotor iron losses into consideration, we computed them using a $2 \mathrm{D}$ finite element model in $\mathrm{JMAG}^{\circledR}$ for the reference motor $M_{l}$. This leads to an average value of the rotor iron losses noted $P_{r e f}$ corresponding to the stack length of the reference motor $l_{\text {ref. }}$. Thus, the rotor iron losses for other similar structures having a stack length $l_{s}$ is estimated using simple scaling as given by:

$$
P_{\text {rotor }}=\frac{P_{\text {ref }}}{l_{\text {ref }}} l_{s}
$$

The total iron losses in the motor are given by:

$$
P_{i l}=P_{s t}+P_{s y}+P_{\text {rotor }}
$$

TABLE II. M400P50 IRON LOSS PARAMETERS

\begin{tabular}{cccccc}
\hline \hline & $k_{H}$ & $\alpha_{i r}$ & $k_{E C}$ & $\gamma$ & $k_{E X C}$ \\
\hline Value & 0.0248 & 1.7297 & 0.0040 & 0.1556 & 0 \\
\hline
\end{tabular}

\section{THERMAL MODEL}

Thermal aspects in permanent magnet motors are of great importance since they affect the magnetic and the electric properties of the materials. In this study, a 3D nodal approach is used to calculate the temperature in the different parts of motor by considering the heat flow in the radial and the axial directions [12]. The motor operates at the steady state. Thus, the model is based on equivalent thermal resistances that account for the conductive heat transfer in solids and for the convective heat transfer in the airgap, the endcap and the casing. An axial symmetry is assumed so half of the machine can be modeled.

The governing equations are based on the method described in [12]. However, some thermal properties involved in the modeling are relatively difficult to estimate. This is the case of the stator slot because this area is non-homogenous and the case of the airgap because of the fluid dynamics that govern the heat transfer. Thus, the winding thermal conductivity is homogenized using the following expression given in [13]:

$$
\lambda_{\mathrm{w}}=\lambda_{\text {res }} \frac{\left(1+K_{\text {fill }}\right) \lambda_{\text {Cu }}+\left(1-K_{\text {fill }}\right) \lambda_{\text {res }}}{\left(1-K_{\text {fill }}\right) \lambda_{C u}+\left(1+K_{\text {fill }}\right) \lambda_{\text {res }}}
$$

where $\lambda_{C u}$ and $\lambda_{\text {res }}$ are the copper and the resin thermal conductivities respectively. Concerning the airgap, since the motor rotates at low speed $(500 \mathrm{rpm})$, the calculation of the convective heat transfer coefficient is based on Taylor $\left(T_{a}\right)$ and Nusselt $\left(N_{u}\right)$ numbers [14]. It is given by:

$$
h_{\text {airgap }}=\frac{N_{u} \lambda_{\text {air }}}{2 e_{\text {airgap }}}
$$

where $\lambda_{\text {air }}$ is the air thermal conductivity and $e_{\text {airgap }}$ is the airgap length. The thermal network takes into consideration the insulation between the stator teeth and the slot winding. Besides, the contact resistance between the stator back iron and the casing is also considered.

As for the end-winding (Fig. 8), they are modeled by three thermal resistances (Fig. 10): $R_{\text {ewl }}$ accounting for the axial heat transfer, $R_{\text {ew2 }}$ and $R_{\text {ew3 } 3}$ accounting for the radial heat transfer of the curved parts. In case of distributed winding, the author in [12] modeled the curved parts as a toroidal structure. However, because we are dealing with concentrated tooth winding, we propose to model the curved parts as cylindrical structures having a length equal to $l_{e w}$. The resistances are given by (20) and (21) where $N_{\text {slots }}$ is the number of slots and $k$ is a hot-spot to mean temperature ratio. 


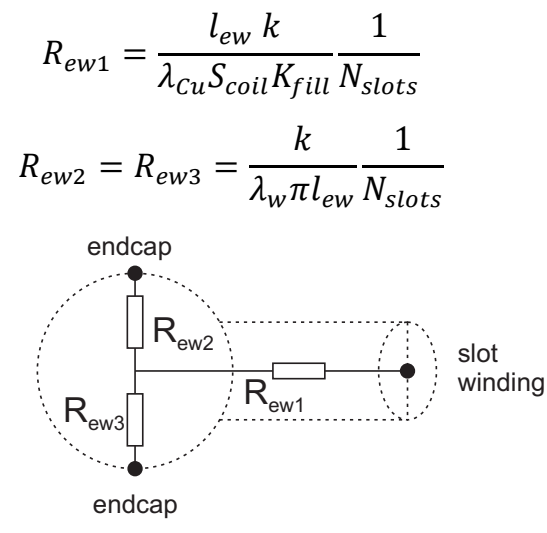

Fig. 10 End-winding equivalent circuit

The general scheme of the thermal network is shown in Fig. 11. The reference temperature is the ambient temperature $T_{0}$. The heat sources are the copper losses in the slot winding and in the end-winding, the iron losses in the stator teeth, the stator yoke and the rotor. The motor is air-cooled using an independent fan that rotates at a constant speed with a constant flow rate. The thermal model is a linear system given by:

$$
[A]^{T}[G][A][T]=[P]
$$

where $[\boldsymbol{A}]$ is a matrix that describes the heat flow direction through an edge (i.e. between two nodes), $[\boldsymbol{G}]$ is a diagonal matrix that contains the conductance of each branch, $[\boldsymbol{P}]$ is a vector that contains the heat sources at each node and $[\boldsymbol{T}]$ is a vector that contains the nodal temperatures. The matrix $[\boldsymbol{A}]$ is created with the sign convention given in Fig. 12. The matrices dimensions are given by (23) where $N_{e d g}$ is the number of edges and $N_{\text {nod }}$ is the number of nodes contained in the thermal network.

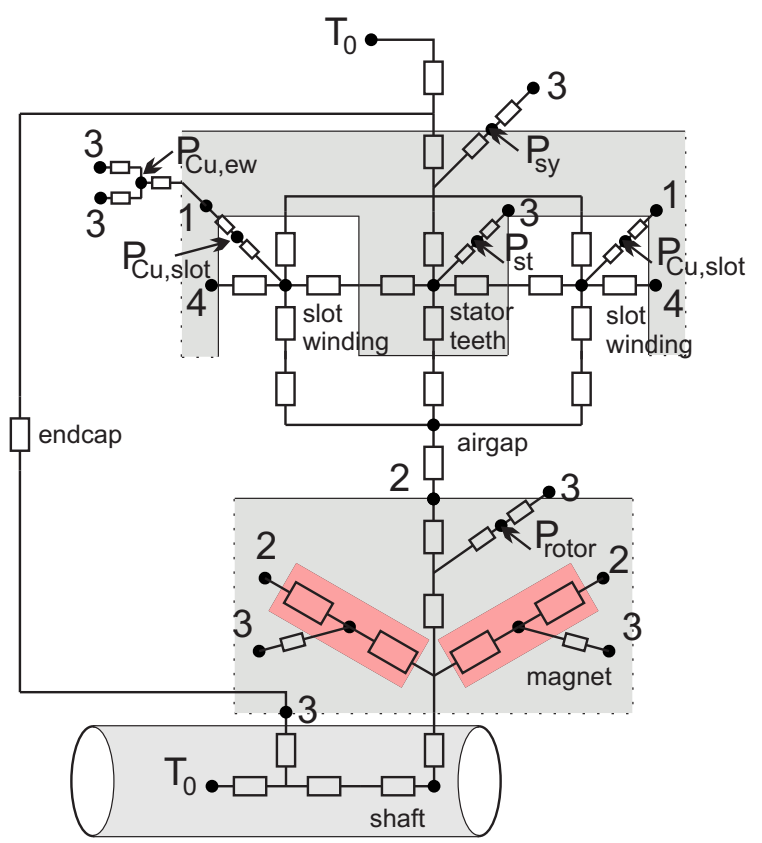

Fig. 11. Thermal network general scheme
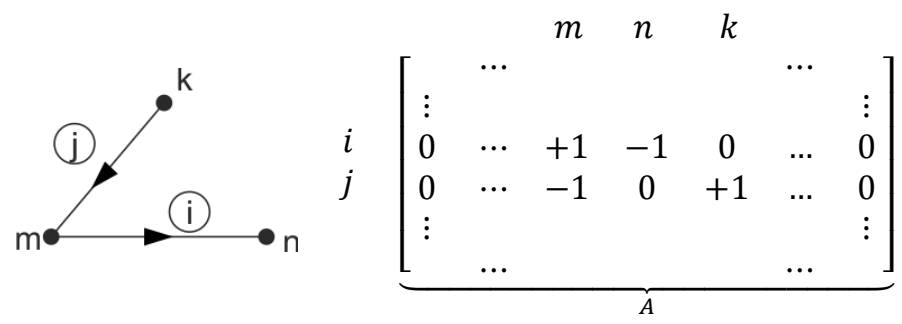

Fig. 12 Sign convention for creating the matrix $[\boldsymbol{A}]$

$$
\begin{aligned}
& {[\boldsymbol{A}]:\left(N_{\text {edg }} \times N_{\text {nod }}\right) ; \quad[\boldsymbol{G}]:\left(N_{\text {edg }} \times N_{\text {edg }}\right)} \\
& {[\boldsymbol{T}]:\left(N_{\text {nod }} \times 1\right) ;[\boldsymbol{P}]:\left(N_{\text {nod }} \times 1\right)}
\end{aligned}
$$

The resolution of (22) leads to the nodal temperatures, among which the copper and the magnet temperatures are of interest.The results are compared with MotorCad $^{\circledR}$ and reported in TABLE III. They show that the nodal thermal network is capable of predicting the temperature in the motor with a discrepancy around $4 \%$.

TABLE III. TEMPERATURE COMPARISON WITH PROTOR $=60 \mathrm{~W}$ PSTATOR $=130 \mathrm{~W}$ AND PCU $=800 \mathrm{~W}$

\begin{tabular}{cccc}
\hline \hline & $\begin{array}{c}\text { Model } \\
\left({ }^{\circ} \mathrm{C}\right)\end{array}$ & $\begin{array}{c}\text { MotorCad }^{\circledR} \\
\left({ }^{\circ} \mathrm{C}\right)\end{array}$ & $\begin{array}{c}\text { Discrepancy } \\
(\%)\end{array}$ \\
\hline End-winding & 80.77 & 77.57 & 4.12 \\
Slot winding & 74.05 & 71.07 & 4.19 \\
Magnets & 71.33 & 69 & 3.38 \\
\hline
\end{tabular}

\section{COUPLED MULTI-PHYSICS MODEL}

The different analytical models are coupled via their inputs and their outputs. Fig. 13 shows a block diagram of the multiphysics coupling. The geometrical dimensions are the main inputs for the coupled model. The magnetic model delivers the electromagnetic torque, the internal power factor and the internal voltage. They are used by the electrical model in order to calculate the power factor and the voltage at the motor terminals. The loss model uses the flux density in the stator given by the magnetic model along with the phase resistance to compute the iron and the copper losses of the motor. The losses are used as inputs for the thermal model that gives the temperature across the structure.

The temperature of the magnets is a key parameter that affects the magnetic performances of the motor by changing the magnet remanence according to (24). The winding temperature changes the copper resistivity according to (25) and affects the phase resistance. Thus, the temperature of the magnets $\left(T_{p m}\right)$ and the copper $\left(T_{C u}\right)$ are used to update the magnetic and the electrical models. The thermal stability is obtained by solving the coupled problem using a fixed point method [11].

$$
\begin{gathered}
B_{r}\left(T_{p m}\right)=B_{r}\left(T_{0}\right)\left(1+\alpha_{B_{r}}\left(T_{p m}-T_{0}\right)\right) \\
\rho\left(T_{C u}\right)=\rho\left(T_{0}\right)\left(1+\alpha_{C u}\left(T_{C u}-T_{0}\right)\right)
\end{gathered}
$$

where $B_{r}$ is the magnet remanent flux density and $\rho$ is the copper resistivity. $\alpha_{B r}$ and $\alpha_{C u}$ are the temperature coefficients of the permanent magnets and the copper respectively. 


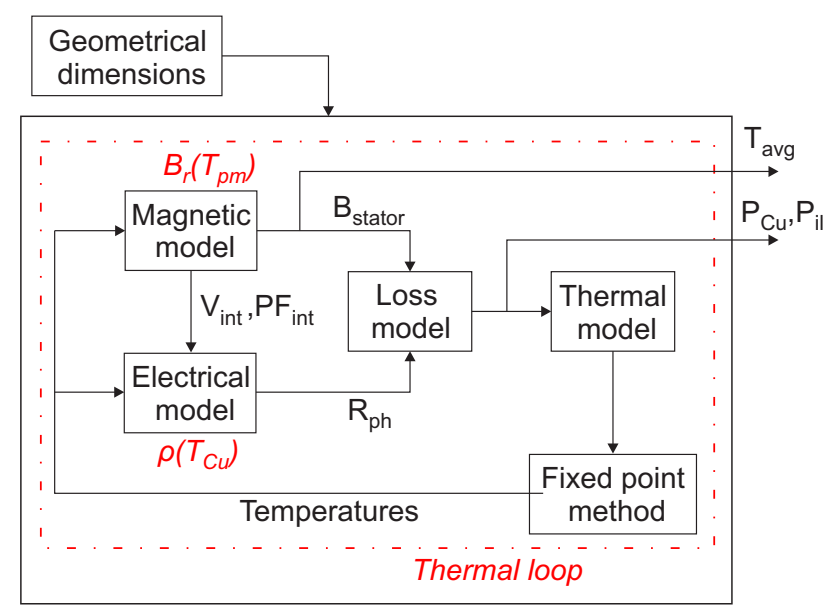

Fig. 13. Multi-physics coupling block diagram

\section{Multi-Physics Model OPTIMIZATION}

The design of an electrical machine for a given application aims to fulfill the required specifications which usually lead to contradictory objectives such as minimizing the volume or the cost and maximizing the torque or the efficiency. The multiphysics optimization approach allows considering the different physical aspects of the motor and leads to an optimal design that meets the given specifications.

\section{A. Optimization problem}

In this study, the objectives are maximizing the efficiency $\eta$ and minimizing the cost $c$, their expressions are given by (26) and (27) respectively. Thus, the design problem is turned to a bi-objective optimization problem under constraints.

$$
\begin{gathered}
\eta=\frac{T_{\text {avg }} \Omega}{T_{\text {avg }} \Omega+P_{C u}+P_{i l}} \\
c=\text { cost }_{\text {copper }}+\text { cost }_{\text {iron sheets }}+\text { cost }_{\text {magnets }}
\end{gathered}
$$

where $\Omega$ is the rotational speed in $r d / s$,

The minimum and maximum limits of the optimization variables $x$ are given in TABLE IV. We have considered 7 geometrical variables: the airgap radius, the tooth angle, the stack length, the tooth height, the barrier tilt angle, the barrier opening angle ratio and the barrier width. They are shown in Fig. 14. Besides, the number of turns in the stator winding, the current angle and the current density are added as variables.

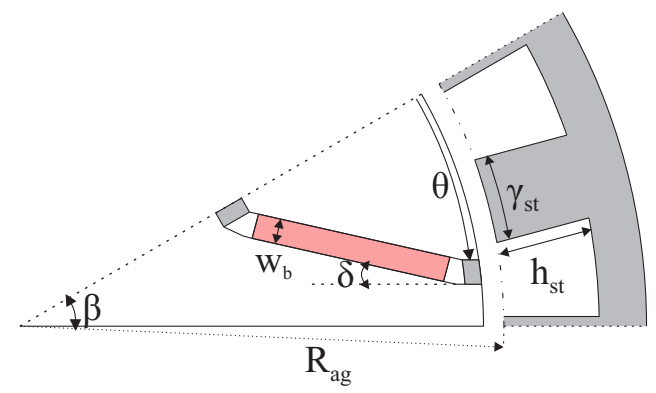

Fig. 14 Geometrical optimization variables

The constraints are used to limit the solutions found in the research space. The targeted machine has to develop an average torque above $210 \mathrm{Nm}$. Its power factor must be greater than 0.85 with a voltage and a current below $365 \mathrm{~V}$ and $40 \mathrm{~A}$ respectively (28). Furthermore, a demagnetization constraint is considered. The magnets magnetic field $H_{p m}$ is calculated assuming two times the current value with a current angle of $90^{\circ}$ elec which reflects a phase opposition between the stator the rotor fluxes [15]. The demagnetization condition assures that $H_{p m}$ is below the intrinsic coercive magnetic field of the magnets $H_{c J}$.

The optimization problem is formulated as follows:

$$
\begin{gathered}
\left\{\begin{array}{cl}
\max \quad \eta(x) \\
\min \quad c(x)
\end{array}\right. \\
\text { Under constraints: } \\
\text { Torque }>210 \mathrm{Nm} \\
\text { Power Factor }>0.85 \\
\text { Voltage }<365 \mathrm{~V} \\
\text { Current }<40 \mathrm{~A} \\
H_{p m}<H_{c J}=275 \mathrm{kA} / \mathrm{m}
\end{gathered}
$$

TABLE IV. OPTIMIZATION VARIABLES

\begin{tabular}{lcc}
\hline \hline \multicolumn{1}{c}{$x$} & $\min$ & $\max$ \\
\hline Airgap radius: $R_{a g}[\mathrm{~mm}]$ & 80 & 93 \\
Tooth angle: $\gamma_{s t}\left[{ }^{\circ}\right]$ & 5 & 12 \\
Stack length $[\mathrm{mm}]$ & 200 & 250 \\
Tooth height: $h_{s t}[\mathrm{~mm}]$ & 20 & 30 \\
Nb. of turns & 8 & 25 \\
Barrier titlt angle $: \delta\left[^{\circ}\right]$ & 0 & 6 \\
Barrier opening angle ratio: $\theta / \beta$ & 0.1 & 0.9 \\
Barrier width $: w_{b}[\mathrm{~mm}]$ & 3 & 4 \\
Current angle $\left[{ }^{\circ} \mathrm{elec}\right]$ & 0 & 40 \\
Current density $\left[\mathrm{A} / \mathrm{mm}^{2}\right]$ & 4 & 7 \\
\hline
\end{tabular}

\section{B. Optimization method and results}

The previously defined optimization problem includes non-linear objective functions and a complex coupling between different domains of physics. Besides, a multiple set of solutions known as Pareto-optimal solutions is researched. Thus, in order to solve this constrained multi-objective problem, the non-dominated sorting genetic algorithm NSGAII is used [16]. It is a multi-objective evolutionary algorithm that uses the non-domination ranking and the crowding distance procedure in order to select the best individuals that will be used to create the next generation. The optimization procedure is performed for a population of 400 individuals and 150 generations. The results lead to a tradeoff between the objectives and are represented by a Pareto front in Fig. 15.

The evolution of the airgap radius, the number of turns, the barrier width and the current density along the Pareto front as a function of the cost are represented in Fig. 16. The airgap radius is quasi-saturated. It reflects the fact that the rotor surface needs to be as large as possible so the 16 poles can be fitted in. The number of turns varies along the Pareto front. In most cases, it remains below the upper limit. The ferrite magnet width is strictly related to the barrier width and its evolution shows that the algorithm is capable of finding different machines without imposing the magnet width to its maximum. The current density decreases along the Pareto 
front. One can choose to minimize the current density but the cost will increase.

The evolution of the constraints as a function of the cost along the Pareto front is given in Fig. 17. When looking to the voltage at the lower part of the Pareto front, one can notice low values compared to the constraint limit. Thus, for a fixed current density and fixed slot geometry, the number of turns can be increased so the current is decreased and the voltage gets closer to its upper constraint limit. The voltage and current values are key parameters for the motor drive design.

The two ends of the Pareto front are made of machines: $\{94.2 \%, 1 \mathrm{pu}\}$ and $\{92.8 \%, 0.8 \mathrm{pu}\}$ Thus, a cost reduction of about $20 \%$ and an efficiency improvement of $1.4 \%$ can be achieved between the extremum points of the Pareto front.

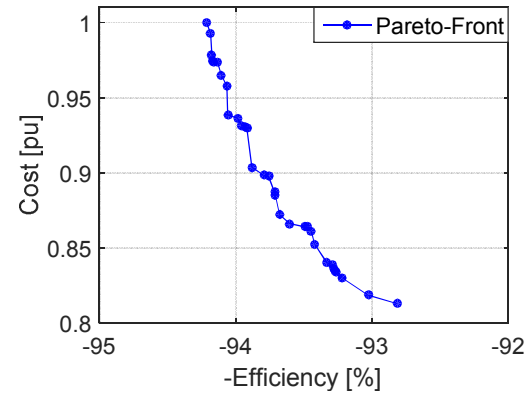

Fig. 15. Pareto front as a result of the optimization problem
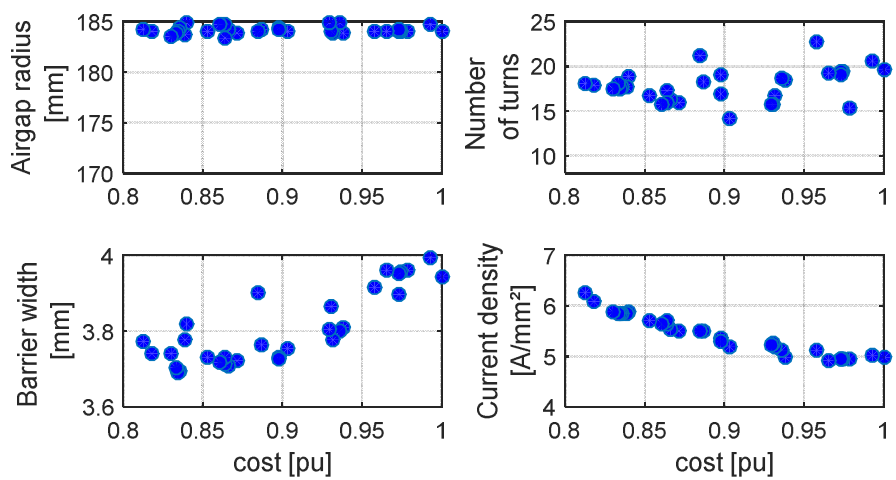

Fig. 16 Evolution of the optimization variable along the Pareto front

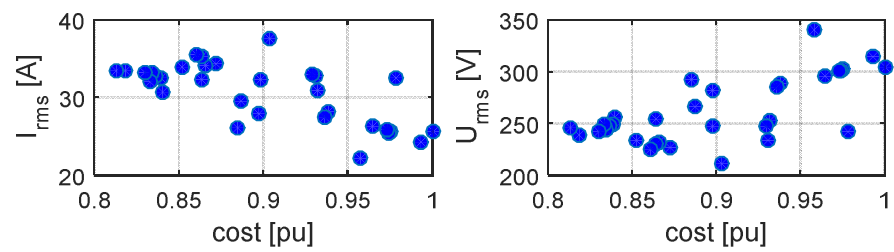

Fig. 17 Evolution of the optimization constraints along the Pareto front

\section{VIII.CONCLUSION}

This paper presented a multi-physics analytical model of a multi-V-shape IPM with concentrated winding. The results of the developed magnetic and loss models have been compared to finite element analysis and showed very good agreement. The thermal model results have been compared to a MotorCad ${ }^{\circledR}$ model and also showed a good accuracy. Finally, the design of the motor for a high torque and low speed application using a multi-physics optimization method has been presented and the results showed a potential cost reduction of $20 \%$ and an efficiency improvement of $1.4 \%$ between the extremum points of the Pareto Front. An experimental validation of the multi-physics model will be presented in a future work.

\section{REFERENCES}

[1] N. Bianchi and S. Bolognani, "Interior PM synchronous motor for high performance applications," in Proceedings of the Power Conversion Conference, 2002, vol. 1, pp. 148-153.

[2] E. Dlala, M. Solveson, S. Stanton, Z. Tang, M. Christini, R. Ong, and B. Peaslee, "Efficiency map simulations for an interior PM motor with experimental comparison and investigation of magnet size reduction," in IEEE International Electric Machines Drives Conference (IEMDC), 2013, pp. 23-29.

[3] T. Raminosoa, D. A. Torrey, A. El-Refaie, D. Pan, S. Grubic, and K. Grace, "Robust non-permanent magnet motors for vehicle propulsion," in IEEE International Electric Machines Drives Conference (IEMDC), 2015, pp. 496-502.

[4] A. Castagnini, A. Curci, and P. S. Termini, "Electromechanical tradeoff analysis of PM-assisted Synchronous reluctance motors," in 2015 IEEE International Electric Machines Drives Conference (IEMDC), 2015, pp. 287-292.

[5] E. E. Montalvo-Ortiz, S. N. Foster, J. G. Cintron-Rivera, and E. G. Strangas, "Comparison between a spoke-type PMSM and a PMASynRM using ferrite magnets," in IEEE International Electric Machines Drives Conference (IEMDC), 2013, pp. 1080-1087.

[6] P. Akiki, M. H. Hassan, J. C. Vannier, M. Bensetti, B. Dagusé, and M. McClelland, "Performance comparison of a doubly-salient motor with multi-V-shape ferrite magnets," in International Symposium on Power Electronics, Electrical Drives, Automation and Motion (SPEEDAM), 2016, pp. 205-212.

[7] P. Akiki, M. H. Hassan, J. C. Vannier, M. Bensetti, B. Dagusé, D. Prieto, and M. McClelland, "Non-linear analytical model for a multiv-shape IPM with concentrated winding," in 2016 XXII International Conference on Electrical Machines (ICEM), 2016, pp. 479-485.

[8] C. G. Broyden, "A class of methods for solving nonlinear simultaneous equations," Math. Comp., vol. 19, no. 92, pp. 577-593, 1965.

[9] D. C. Hanselman, Brushless Permanent Magnet Motor Design. Writers' Collective, 2003.

[10] I. Petrov and J. Pyrhonen, "Performance of Low-Cost Permanent Magnet Material in PM Synchronous Machines," IEEE Trans. on Industrial Electronics, vol. 60, no. 6, pp. 2131-2138, Jun. 2013.

[11] X. Jannot, J. C. Vannier, C. Marchand, M. Gabsi, J. Saint-Michel, and D. Sadarnac, "Multiphysic Modeling of a High-Speed Interior Permanent-Magnet Synchronous Machine for a Multiobjective Optimal Design," IEEE Trans. on Energy Conversion, vol. 26, no. 2, pp. 457-467, Jun. 2011.

[12] P. H. Mellor, D. Roberts, and D. R. Turner, "Lumped parameter thermal model for electrical machines of TEFC design," IEE Proceedings B - Electric Power Applications, vol. 138, no. 5, pp. 205218, Sep. 1991.

[13] L. Idoughi, X. Mininger, F. Bouillault, L. Bernard, and E. Hoang, "Thermal Model With Winding Homogenization and FIT Discretization for Stator Slot," IEEE Transactions on Magnetics, vol. 47, no. 12, pp. 4822-4826, Dec. 2011.

[14] J. F. Trigeol, Y. Bertin, and P. Lagonotte, "Thermal modeling of an induction machine through the association of two numerical approaches," IEEE Transactions on Energy Conversion, vol. 21, no. 2, pp. 314-323, Jun. 2006.

[15] T. H. Akinaga, T. Staudt, P. E. da Silva, and A. A. Espindola, "FEAbased method for estimating PM demagnetization in electrical motor design: Development and experimental validation," in 2016 XXII International Conference on Electrical Machines (ICEM), 2016, pp. 1749-1755.

[16] K. Deb, A. Pratap, S. Agarwal, and T. Meyarivan, "A fast and elitist multiobjective genetic algorithm: NSGA-II," IEEE Transactions on Evolutionary Computation, vol. 6, no. 2, pp. 182-197, Apr. 2002. 